\title{
An Action Research Report on Applying Co-Operative Learning Techniques in an Intensive English Reading Class in China
}

\author{
$\mathrm{Xiao} \mathrm{Fu}^{1}$ \\ ${ }^{1}$ College of Foreign Languages, Chongqing Jiaotong University, China \\ Correspondence: 66 Xuefu Avenue, Nan'an, Chongqing 400074, China. TEL: 86-23-6238-9524. E-mail: \\ 17685878@qq.com
}

Received: June 8, 2013 Accepted: July 6, 2013 Online Published: September 4, 2013

doi:10.5539/elt.v6n10p17 URL: http://dx.doi.org/10.5539/elt.v6n10p17

\begin{abstract}
This study is to examine whether the implementation of CL in an intensive reading class has a positive effect on improving the passive situation of students, whether it helps activate their enthusiasm for and ease their anxiety of participation in language class activities, and whether it is helpful to their improvement of English proficiency. The research questions to be addressed in the study are: 1) what, if any, psychological changes appear to happen to students in a co-operative learning situation? 2) In what ways do students behave differently in a co-operative learning classroom? 3) What difficulties might teachers have in implementing co-operative learning and how can they be overcome? To answer these questions I conducted a 16-week action research project in one of my classes. The whole process of the research was divided into three stages with cycles of planning, implementing and reflecting on progress. Classroom observation, teacher's diary, questionnaire and informal interview were used as instruments to collect data for reflection throughout the research. The final results show that, CL does have some positive effects on improving the present passive situation in my English classroom. However, there are some problems arising from the action research.
\end{abstract}

Keywords: cooperative learning, action research, English as a Foreign Language (EFL) learner

\section{Introduction}

\subsection{The Current Course Intensive Reading Class}

Intensive Reading, as its name suggests, is a type of reading practice, by training students' various reading skills of skimming, scanning, summarizing, inferring, and evaluating; on the other hand, it aims to enhance learners' language proficiency, thus it also encompasses the training of other language skills, such as listening, speaking, writing and translating. In addition to the training of linguistic competence, communicative, social and strategic competences are due to be trained through co-operative efforts in identifying, analyzing and solving problems and in fulfilling learning tasks. The approach of co-operative learning, therefore, has enormous potentialities in this type of class.

\subsection{Problem Identification}

In typical classrooms, the desks are designed for taking lecture notes and are, of course, all facing the teacher's desk or lectern. Frequently heard expressions are, "No talking", "Keep your eyes on your own paper", "Don't help others or ask them for help". In short, students are regarded as containers to be filled with knowledge by the teacher. This Tian Ya Shi or "feeding the duck" methodology, (also called "jug and mug" method), the teacher is a full jug, who pours knowledge into the students, who are empty mugs and this results in dull and inflexible classroom atmosphere.

The following are the main phenomena in traditional classroom: 1) Teachers use most class time to explain and impart knowledge, while students act as listeners. 2) There is a little interaction between teachers and students or among students. 3) Classroom atmosphere is dull and boring. 4) Many students take a sleep in class.

I too have taught my students with the traditional teaching method for half an academic year. The students did not take an active part in the classroom activities; they were reluctant to ask or answer questions, thus it was me who did all the work, explaining everything and talking for $99 \%$ of the class time. I once tried to change this style of teaching by explaining the text in less detail and giving them more chances to speak and ask questions in 
class. However, the result was very disappointing. The following comments were elicited from some of my students:

1) "I just know I have some kind of disability: I can't learn a foreign language no matter how hard I try"

2) "When I'm in my English class I just freeze! I can't think of a thing when my teacher calls on me. My mind goes blank"

3) "I feel dislike English when I started to learn it. I spend most of my time to learn it but no any progress. I hate it."

4) "It's about time someone studied why some people can't learn languages."

Even more, in the classroom situation they were not courageous when asked in teacher-student interaction activities lest they lose face with their friends because they made some mistakes. So their passivity was found everywhere in the whole process of classroom learning.

Thus, based on above mentioned considerations, the aim of the study has been initiated: it is intended to demonstrate whether the introduction of co-operative learning to college English intensive reading teaching has a positive effect on improving present situation of English learning for students and whether it helps activate their interest and ease their language anxiety to participate in class activity, and finally whether it is helpful to the improvement of English proficiency.

\section{Literature Review}

\subsection{Definition of Co-Operative Learning and Clarification Terms}

Co-operative learning (CL), according to Kohonen (1992), is a type of "experiential model" of learning which differs greatly from the "transmission model". The "transmission model" considers the teacher the person to "impart knowledge and the skills to the learners" and students "passive recipients of knowledge" (Kohonen, 1992:30), whereas the "experiential model" highlights the experience or the process of learning in which "a learning atmosphere of shared partnership, a common purpose and a joint management of learning" might be provided (ibid. p31).

The essence of CL, as illustrated above, lies in the cooperation among learners inside the classroom; however, CL also encompasses learners' collaboration outside the classroom, which is the extension of in-class cooperation. Moreover, CL also includes the cooperation between the teacher and students and major forms underlying this type of collaboration are teacher's teaching, teacher-students discussion and students' group or pair discussion under the teacher's guidance.

Hence, in CL, the teacher's role is an "organizer", a "moderator", a "helper", an "evaluator" and "the information resource" as opposed to those according to the transmission model: "dominator" and "information or knowledge provider".

Christison, defines CL as "a strategy for the classroom that is used to increase motivation and retention, to help students develop a positive image of self and others to provide a vehicle for critical thinking and problem solving and to encourage collaborative social skills" (Christison, 1990: 140).

However, according to Christison, implementation of CL in the classroom can only be successful under the following conditions. Firstly, she asserts that since human beings are not gifted with the ability to cooperate with each other, co-operative skills must be learned, like various skills in content areas. Secondly, learning activities and sitting in the classroom must be structured to guarantee face-to-face interaction and cooperation among students. Finally, a successful process of cooperation requires each individual to share responsibilities rather than the monopoly by one member (ibid).

Johnson and Johnson further clarify the concept of CL by asserting that in the co-operative classroom "interaction is characterized by positive goal interdependence with individual accountability. Positive goal interdependence requires acceptance by a group that they 'sink and swim together".

To sum up, almost all researchers, through various works and articles, use such terms as "positive interdependence", "mutual support" and "individual accountability" to illustrate the concept of CL. It might be misleading that CL is confined to learners' working in group and helping each other. Besides group work, however, it must also satisfy the following conditions: "face-to-face" interaction by all students, "heterogeneous teams, "structured goal interdependence", "individual accountability" and "an emphasis on practicing social skills" (Totten, 1991:1). 


\subsection{Major Co-Operative Learning Methods}

In order to implement co-operative learning in the actual classroom, researchers in the field have developed various methods, which can be also termed as "approaches"; whatever the approach, there is one thing in common in the formation of co-operative learning teams: the integration of students of mixed-levels (Putnam, 1993).

\section{Learning Together}

This method was developed by Johnson and Johnson in 1975 (Knight and Bohlemeyer, 1990). The typical collaborative classroom using this method would be group members working together to accomplish one assigned group task; during the learning process, students provide mutual support to ensure that everyone in the group is involved and understands. If any difficulty occurs, they would have discussions first and the teacher's help becomes the final rescue. In terms of assessment, collaborative groups are evaluated and rewarded based on their general group performances (ibid).

This method is usually employed in foreign language teaching in the form of "Role-play" which takes place in class after the reading stage. By role-play, we mean that students, in pairs or groups, assume certain roles in a certain situation, or act as themselves to cope with a given problem (Chen and Xing, 1997). In role-play the learner is able to exercise his or her own initiative and creativity in using the target language. It aims at developing the learner's communicative competence. In China, the English class for non-English majors at college level provides little opportunity for oral interaction. One solution to this problem is to adopt "role-play".

\section{Jigsaw Methods}

The original Jigsaw was developed by Aronson and his colleagues in 1978 (Knight and Bohlemeyer, 1990). According to this method, each student in the collaborative group only has one part of the learning material and he or she is responsible for learning, understanding as well as teaching this part to the rest of the group members. However, before going back to their original collaborative group to teach, students who receive the same part of the material form the counterpart group to study together the assigned task. What lacks, however, in this method is that there is no group evaluation mechanism, except that individual student is evaluated on the basis of individual examination after learning (ibid).

In Jigsaw II, which was developed by Slaving in 1980, a competitive mechanism among co-operative groups is introduced; group rewards are offered based on the accumulation of each group member's individual performance during the learning process. Hence, co-operative groups compete against each other and each learner has equal chance to contribute to his or her group.

This method and a paired-reading method to be discussed later may be changed into group work in the light of English as foreign language context, which aims at training of social competence.

\section{Group Investigation (GI)}

GI which was gradually developed by Sharan and his colleagues from 1976 onwards (Knight and Bohlemeyer, 1990) is a highly structured method and is, to some degree, similar to Learning Together, in that members in each group sit together to learn their part. According to GI, different groups get different tasks under a general topic; therefore there are some basic characteristics underlying the method. Firstly, the class is divided into several co-operative groups, each of which takes the responsibility of investigating its assigned subtopics and is ready for presentation in front of the whole class. Secondly, the division of the labour must be reasonable and meaningful to ensure the interdependence of group members. Thirdly, students communicate with each other in the team when gathering information, planning, analyzing and evaluating. Finally, in terms of the teacher's role, he or she is a resource person and an indirect leader, ready to provide direction, explanation and to motivate students during the learning process.

Hence, in this method, collaborative skills are taught and reinforced through the group learning process; in addition, positive interdependence and individual accountability are encouraged while collaborative members are dividing labour among themselves.

In EFL (English as Foreign language) classroom, group investigation may be employed in the form of class report, group discussion and competition. GI can be employed at all learning stages: at pre-reading, while-reading and post-reading stage, and it also can be used in dealing with exercises. By GI, the students' investigation and presentation skills may be improved, and the students may become more autonomous.

Summary of the Co-operative Learning Methods

Through the explanation and description of them, one might understand better the strict mechanism underlying 
them: positive interdependence, individual accountability, and co-operative skills. In specific teaching situations of the language learning classrooms, these methods may be employed in the form of pair work, class report, group discussion, role-play, and group competition.

\section{Research Methodology}

\subsection{Instruments}

Classroom observation, reflective journal, informal interviews, and questionnaires were used as instruments to collect data in my research. Appendix A provides the details of the instrument sheets.

\subsection{The Sample}

Subjects for the whole study were 58 college students majoring in computer science. This class was randomly selected from one of my teaching classes for the semester.

All the participants were first-year Non-English majors from the same class who had attended the university for half a year, aged from 18 to 20 .

Among the sample population 24 were females and 34 were males. They had learned English for at least six years before their enrolment in this university. The students have different personalities and different proficiency levels in English learning.

\subsection{The Research Process in Action and Reflections}

The whole process of the research can be divided into three stages (the whole research lasted 4 months, in the 2012 academic year):

1) The preparation stage (at the opening of the semester, from 1st, Mar, to 12, Mar)

2) The action stage (before and after the midterm): cyclically, modifying and adjusting the application of co-operative learning with observation and interaction and further modification and adjustments (from 15, Mar. to 15 , June)

3) The assessment and reflection stage (before the end of the semester): assessing the effects of co-operative learning on students' learning and psychological changes and reflecting upon the problems arose from the research (from 16, June to 30, June).

\subsubsection{Preparation Stage}

The questionnaire I (see Appendix D) with 32 statements was designed and distributed to the students to evaluate their reflections in their former traditional English class. 58 questionnaires were distributed, but only 40 were collected.

To apply co-operative learning to Intensive English Reading classroom, both students and I need to be adequately prepared. So before conducting co-operative learning, I introduced the definition, characteristics, purpose and rules of co-operative learning to my students, and made sure they had a good understanding of co-operative learning. For Chinese students, this explanation was presented in such a way that students understand that co-operative groups are seen as a mutual-responsibility activity; they are not criticizing, but helping each other. Toward this end, I took advantage of those aspects of the Chinese collectivist culture that can be used to help build up "a sense of community" (Carson, 1992:112). Students showed their understanding and their support. Their acceptance encouraged me to go on with this research.

The second thing is about grouping. Co-operative groups cannot be structured deliberately according to one of the elements of co-operative learning, face-to-face "promotive" interaction; co-operative groups should be purposefully heterogeneous. Because of the size of the class, I divided students into 10 groups, 6 students in the first nine groups and 4 in the last one group. In order to ensure heterogeneity, students are placed in groups that are mixed by academic skills, social skills, and sex. This can maximize each student's contributions to the groups and provide each student with opportunities to learn from other individuals.

Finally, I let students themselves choose their group leader, secretary and inspector in each group. This was to ensure everyone had her/his own role in the group and to takes her/his own responsibility, namely, every student in the group has got a specific job. I declared that a group leader was in charge of task subdivision, checking other group mates' contribution to the group, and leading the group work in the correct direction and so on. A secretary is in charge of taking notes of the group mates' ideas during group discussion. An inspector is in charge of making sure that group obeys co-operative learning rules, e.g., every member of the group uses the target language. I also told them, after students finishing group task, I would call a student by random to be the spokesman who should report his group achievement on behalf of his group. In this way, every member of the 
group had some responsibility and every student in the group would listen to other people carefully and every member was preparing to speak. So no matter what level the students are at, they would be encouraged to work, become active, attentive, and responsible.

\subsubsection{Action Stage}

Planned Actions:

Based on the fully understanding of co-operative learning, I assumed that the learning of one unit in the book of Intensive Reading generally followed the procedures below:

1. Co-operative preparation work before the actual classroom learning.

1) Co-operative members go out to find resources so as to provide relevant background information about the coming reading passage.

2) Co-operative members divide labor among themselves, consult the dictionary or other reference books available to them, learn new or difficult words and structures together and get ready for presenting them in class.

2. Co-operative learning in the classroom.

1) Co-operative teams present their findings in front of the whole class.

2) Co-operative learning activities are designed to guarantee students' comprehension of the reading passage and to promote communicative output among co-operative members.

3) Comprehension of the reading passage and promotion of communicative output among co-operative members.

3. Group processing and evaluation after co-operative learning tasks are completed.

The following co-operative activities were designed and planned to carry out in my Intensive English Reading class.

1. Co-operative preparation work stage

Co-operative learning method: Group investigation.

Group investigation in finding resources of background information: training of Investigation and Presentation Skills

As manifested in the learning procedure of Intensive Reading, various learning tasks are due to be fulfilled co-operatively, thus it becomes impractical for all co-operative teams to complete the same learning task. Group Investigation, therefore, is the most frequently employed method of co-operative learning and is considered by the researcher the most suitable approach in finding out background information.

Such a learning project using Group Investigation generally follows the stages of:

1) Topic orientation: Topic is generally decided by the teacher.

2) Research and data collection: Students in the co-operative team find out necessary resources available to them.

3) Preparing data presentation: Students conduct their assigned learning task and initiate discussions among collaborative members.

4) Presentation: Individual learners from their respective teams conduct presentation on the findings.

5) Evaluation: Teacher comments on learners' performance includes their understanding of the assigned topic, their procedural organization, languages gains and deficits, and possible by-products such as enhancing of motivation in other learners, activating of learning atmosphere (Adapted from Legutke, 1991:169).

Please see Sample One (Appendix C) for further details of the activities.

2. While-reading stage

Co-operative learning methods: Group Investigation, Pair-reading, and Jigsaw.

1) Group Investigation (GI) in Learning Structures; Practicing the Skill of Paraphrasing: Training of the Linguistic Competence.

GI and its succeeding presentation are not only confined to consulting background information; instead, such a didactic skill is reinforced in learning language and structures in the text. This type of language-related learning activity constitutes a crucial part of Intensive Reading. As it is a co-operative effort to consult background 
information, each team would in turn take the responsibility for consulting the dictionary about words and structures assigned by the teacher and for presenting their findings to the whole class.

One problem in traditional methods at the while-reading stage was that whenever it came to explanation of difficult words or phrases, students tended to provide Chinese equivalents rather than use simpler English to paraphrase. Here in the following example I will show how the approach of co-operative learning enables students to incorporate the practicing of the skill of paraphrasing which is a sub-skill of linguistic competence in coping with difficulties in terms of language. Please see the details from Sample Two and Sample Three (Appendix C).

2) Modified Paired-Reading and simplified Jigsaw in comprehending the text: Training of the social competence.

Understanding reading materials in the form of cooperation requires learners' social competence in order to negotiate meaning and to reach agreement. The method of Paired-Reading, as has been illustrated in Chapter Two, is especially designed for reading class and according to the researcher, it is particularly useful for reading narrative writings, since they consist of vivid plots, specific characters and is easy to understand. In the light of the teaching context, we may change the method into group work, which can be exemplified as Sample Four (Please see Appendix $\mathrm{C}$ for the detail).

\section{Post-reading stage}

Co-operative learning methods: Group Investigation; Learning Together:

1) Group Investigation: Training of Social and Strategic Competence.

Post-reading activities are principally designed for learners to practice communicative output in forms of summary reporting, evaluation or suggestion making, and role-play sometimes. Therefore, it is possible for several co-operative tasks to be performed simultaneously. Group Investigation, again, can be employed at this stage. Please see details from Sample Five and Sample Six (please see Appendix C for the detail).

2) Learning Together: Role-play, training of Social and Communicative Competence.

One conspicuous property underlying the approach, of Learning Together is unanimity of the assigned task which is likely to lead to competition among learning teams; moreover, face-to-face interaction among team members, positive interdependence, and individual accountability in the same learning task are unexceptionally practiced by each co-operative team. Unanimity as well as group processing skills can be easily observed. Please see Sample Six (Appendix C) for further detail.

Through such an activity, communicative competence which required learners to understand both linguistic forms and their respective functional meanings would be trained in learners. Such post reading activities in the form of role-play are often designed by the teacher, since it has become "a standard activity for the post-presentation, free language practice phase of a language lesson" (Legutke, 1991:120). It can really provide learners with opportunities to involve and dramatize the story personally which can deepen their understanding of the text. Moreover, it allows learners to be creative and imaginative in the communicative output.

\subsubsection{Reflection and Adjustment}

I kept a diary detailing my reflections on my teaching according to my planned actions. In the first two weeks, students were not accustomed to the way of learning, because their class "had seldom been so student-centered before", as one of my students said to me. In spite of that, students were in high spirits in the English reading class. They felt excited about the new approach and showed more smiles in the class.

However, at the initial stage of implementation of co-operative learning, some chaos arose in the classroom. In my diary (18, Mar. 2012), I recorded "the students ran about from one seat to another; shouts and noise could be heard in every corner of the classroom." Based on previous research, these phenomena are very common in co-operative learning arranged especially by some inexperienced teachers who are not familiar with co-operative learning approach. This chaos, derived from grouping is inevitable in implementing co-operative learning. Literature suggests this is predicable and an indispensable part in "Group Processing". Although concerned, I decided to continue.

I interviewed several students informally; students said that they got too excited to concentrate on their learning task when they were grouped, because most of them needed to change their seats. Also, they told me, though I had already carefully introduced the co-operative learning approach, this learning style was new to them. I persevered, observed and hoped the literature was right. It took time to learn how to learn cooperatively with other classmates. I understood that students were not acquainted with co-operative learning approach, and I tried to facilitate this new approach. 


\section{Adjustments:}

Practice has shown that before learners become fully acquainted with communicative activities in general and co-operative learning in particular, they tend to forget certain basic principles.

I decided then to have four basic rules in my classroom:

1) Speak English

2) Do not talk about irrelevant topics

3) Listen to your group leader

4) Help each other

I wrote these four rules on the blackboard at the very beginning, but I found the learners were not very likely to look at the blackboard while they were engaged in what they were doing, especially if their backs were to the board.

So I decided to write them on the top of the task-sheet, since I prepared the sheets and distributed them among the class, one per group. I wrote these rules with colored inks to make them more attractive.

Besides, I used the stoplight cards to help students with the noise problem. A green card went on a group's desk if they were working together quietly. A yellow card indicated that they needed to be quieted down a bit. When a red card was put on their desk, the group should become completely silent, and all should silently count to 10 before starting to work again.

\section{Reflection Again:}

After the application of the modifications detailed above, several changes were noted in English class. First, the class became more orderly than before. And students made great progress in the class. At the beginning, they were too shy to come to the front and face the whole class. With my insistence, the first students came to the front and rushed through the background information they had selected from a newspaper, and ran back to their seat without interacting with the audience. I then encouraged the class to ask them questions about the information and said their group mates may assist them. As time went on, my diary showed students asked more and more questions to the group speaker. Therefore, this activity is really helpful because on the one hand, it can "force" the students to participate in the class activity; on the other hand, it can also help the students talk more freely in front of a large audience.

Secondly, they appeared to be more active and motivated in the class. Take Sample Five as an example (please see Appendix C for the detail). To the co-operative task of "What would you suggest for the problem?" the students provided general suggestions such as "improve the working conditions", "improve the technique", perhaps because of their lack of knowledge and world knowledge about clothing production. However, in terms of their group processing, students were highly stimulated, actively contributing, and one member was elected as secretary to take notes so as to complete the worksheet. Learners' performance in this activity indicated that the teacher should try every means to design co-operative tasks, meanwhile foster a co-operative atmosphere so as to enable them to be intrinsically motivated. In this way, learners were more likely to take the initiative to manage their own learning and to progress towards the final objective of autonomy.

At the midterm, in 30, Apr. 2012, I reflected on my action research for one month and half. Although students had made some progress in the class, from class observation and students feedback I still found some problems arose from the implementation.

1) As regards the learning of language points in Intensive Reading, because of lack of experience in cooperation, students were eager to copy almost all items from either dictionaries or other resource books, which is time-consuming and unnecessary. They tended to engage themselves in individual work rather than in-group work.

2) In terms of students' presentation skills, learners were in haste to finish their assigned tasks rather than to interact with the audience, because the students felt very nervous when facing the audience. Besides, their inadequate performance such as incorrect pronunciation might hinder other students' correct understanding.

3) Since learners hardly had the chance of conducting learning by themselves in the middle school and since they were not competent enough in using the school libraries, they were less capable of selecting information from various resources and provided lengthy expositions by copying or even photo-copying thick pages of their findings which were always redundant and unnecessary. 
4) As to the evaluation of implementation of co-operative learning, students complained a lot. They said, the evaluation was for each group not for the individual; so everyone in the group can gain the same score no matter how much work he completed. And, for getting better scores, the tasks such as collecting material and role-play were all done by those students with good language proficiency. I noted that some students could get a high score without taking part in the group activities.

5) In co-operative learning, some students became lazy, as they could fully rely on other team members. This phenomenon was affirmed by my colleague who came in to observe the process - some students didn't participate in the group work. The group leaders complained that sometimes the group members gave all the jobs to them. I realized that there were more or less some students who at times didn't do the task assigned, which for learners may be more used to the traditional model of teaching than to the co-operative approach.

6) Sometimes in groups, a few learners dominated co-operative activities, and most of learners did not participate.

Such problems mentioned above are really practical obstacles that affect a thorough implementation of co-operative learning in the Chinese context and hinder the unfolding of the potential underlying this approach.

\subsubsection{Further Adjustment and Further Reflection}

Further Adjustment:

After considering carefully and reading more literature to find the cure, I made some changes in my action research.

1) As far as the problems (1), (2), (3) mentioned above are concerned, students should practice more in classroom activities and meanwhile turn to the teacher for help; on the part of the teacher, I encouraged my students to constantly guide and help learners to develop investigation and presentation skills and help them to learn to explain words and structures via specific linguistic contexts in the reading passages. I had taught students to increase face-to-face interaction with the audience so that they could improve their pronunciation, intonation, fluency, etc. I also recommended that the students use more reference books so as to facilitate their investigative tasks.

2) As far as problem (4) concerned, I adjusted the evaluation criteria a bit. On the base of the evaluation for each group, I added the evaluation for the individual. For each group member, the group evaluation was taken $50 \%$, and the other $50 \%$ depended on the performance of the individual himself.

3) In light of problems (5) (6), more opportunities for cooperation should be provided so as to encourage each individual to participate. So long as the activating role played by each learner can be reinforced, the effect of group processing should be improved.

Further reflection:

Following further reflection I made some changes in my action research and started another phase. The co-operative learning seemed to go smoothly now. Instead of copying books, they knew how to organize their own language by their daily accumulation. In addition, students' presentation skills improved very well. My diary recorded that actually, not only good students made progress but also the weaker learners improved rapidly. For instance, instead of relying on good students, the weaker ones also took an active part in class activities and the students could work both independently and cooperatively. In a word, more and more students participate in my class actively and effectively and the English class was gradually transferred from a boring, teacher-dominated one into an active, effective and student-dominated one in which students' all-round capabilities were developed rapidly.

At the end of this term, I reflected on my action research again. The situation had improved in terms of the problem (1), (2), (3). (4). Students did a better job than before, and they felt more relaxed now. But as far as the problem (5) and (6)), there still remained some questions.

I observed that there were still a small number of learners who might be incompatible with and were not accustomed to requirements set by the co-operative learning due to idiosyncratic factors, which in turn led to much silence and low motivation in learning. And forcing the new approach to learning them seems less ethical. How to make all learners adapt to new modes of learning is still a question.

Secondly, one of the major concerns of co-operative learning is the mutual help and progress achieved by all learners. However, there is a gap between fast learners and slow achievers, because initial success and tendency of being compatible with the method is prone to yield higher motivation and self-esteem which in turn lead to more effort and better achievement. Some introvert learners who were initially unaccustomed to co-operative 
learning showed shyness and reluctance in co-operative learning activities. They were often overshadowed by more extrovert learners. So the result for them was less interest in learning. Such accumulated negative experiences do hinder their language acquisition and produce side-effects on learners' psychological and affective domains. Hence how to minimize the negative effects on learners exerted by co-operative learning called for an immediate solution.

Furthermore, I observed another question which seriously hindered the implementation of co-operative learning. In the Chinese context, English learning belongs to the type of foreign language acquisition in contrast to second language acquisition in some western countries. Not having the immersion linguistic context, my students were more likely to turn to their mother tongue in conducting co-operative learning tasks, which, to some degree, hindered and reduced opportunities to communicate in the target language. This somehow weakened the effects of co-operative learning on language development. How to prevent a learner from using their native language in the Chinese context may always be a problem in any type of communicative language teaching.

Besides, the students' experiences, I reflected on the changes on myself, their teacher. I strongly feel that the students and I now understand each other better after the implementation of the 16-week action research. Before carrying out this action research, I tended to think that the students were too lazy to study in my class, but now I know that they can learn a lot from me after I changed my way of teaching. Rather than the end of the 16-week action research, this is the real beginning of the next cycle of my future career study, in which I will explore further the ways of how to help students learn more efficiently and effectively.

\section{Results}

In addition to my ongoing reflection and changes in the phases of the action research, I decided to measure the progress from the students' perspective. Questionnaire II was distributed to 58 students and 56 students returned the completed questionnaires this time. Part I of questionnaire II is the same as Questionnaire I. Part II of Questionnaire II are 20 statements; students can give their free comments on those statements. The students' comments in the translated version are provided in Appendix E.

The average points for each statement in the Questionnaire I and Part I of Questionnaire II are displayed in Table 1. The average point clearly loses an important level of detail but this will be supplemented by qualitative comment to provide a flavour of the experiences as felt by the students in scoring their responses.

Table 1. Average Points for each statement in the two questionnaires (on a five point scale with 1 strongly disagree to 5 strongly agree)

\begin{tabular}{lll}
\hline Statement No & Average Points from Questionnaire 1 & Average Points From Questionnaire 2 \\
\hline 1 & 2.2 & 3 \\
2 & 1.6 & 1.6 \\
3 & 3.6 & 3 \\
4 & 3.4 & 3.8 \\
5 & 2.4 & 1.8 \\
6 & 3 & 2.8 \\
7 & 2.8 & 2 \\
8 & 3.8 & 3.6 \\
9 & 2.8 & 3.6 \\
10 & 3.4 & 2.4 \\
11 & 3 & 3.4 \\
12 & 2.6 & 2.6 \\
13 & 3.2 & 3.8 \\
14 & 3.4 & 3.6 \\
15 & 3 & 3.2 \\
16 & 1.8 & 2.8 \\
17 & 3 & 3 \\
18 & 2.6 & 2.6 \\
19 & 4 & 3.8 \\
\hline
\end{tabular}




\begin{tabular}{lll}
\hline 20 & 4.2 & 3.2 \\
21 & 3 & 1.8 \\
22 & 2 & 2.8 \\
23 & 2.6 & 2.6 \\
24 & 2.6 & 3.4 \\
25 & 2.4 & 3 \\
26 & 1.8 & 2.2 \\
27 & 2.4 & 3.6 \\
28 & 2.8 & 3.2 \\
29 & 2.8 & 2.2 \\
30 & 1.8 & 2.2 \\
31 & 2.4 & 1.8 \\
32 & 2.6 & 3.4 \\
\hline
\end{tabular}

The design was arranged in three perspectives: self-confidence, anxiety behaviour, and attitudes towards English. Statements 1, 3, 5, 11, 12, 14, 16, 18, 22, 23, 24, 25; 28, 30 were related to student's self-confidence in English; statements $2,6,7,10,15,21,27,29$ to the behaviours of anxiety, such as avoidance of speaking, fear of pressure; and statements 4, 8, 9, 13, 17, 19, 20, 26, 31, 32 reflected attitudes towards English.

Generally speaking, the results from the questionnaires confirm the expectations mentioned in the introduction. We can see in a co-operative learning class, the students become more confident in their English task than in a traditional class, which is due to the relaxed and co-operative environment and much autonomy and little pressure. Secondly, co-operative learning highly motivates learners to produce much output with the help of other group members, the relaxed atmosphere, and interesting topics. Thirdly, the students' English proficiency especially listening and speaking is enhanced more or less. From figure 1, 2, 3 below we can see in diagram format the comparison of the average points of Questionnaire 1 (Q1) and Questionnaire 2 (Q2) on those three issues.

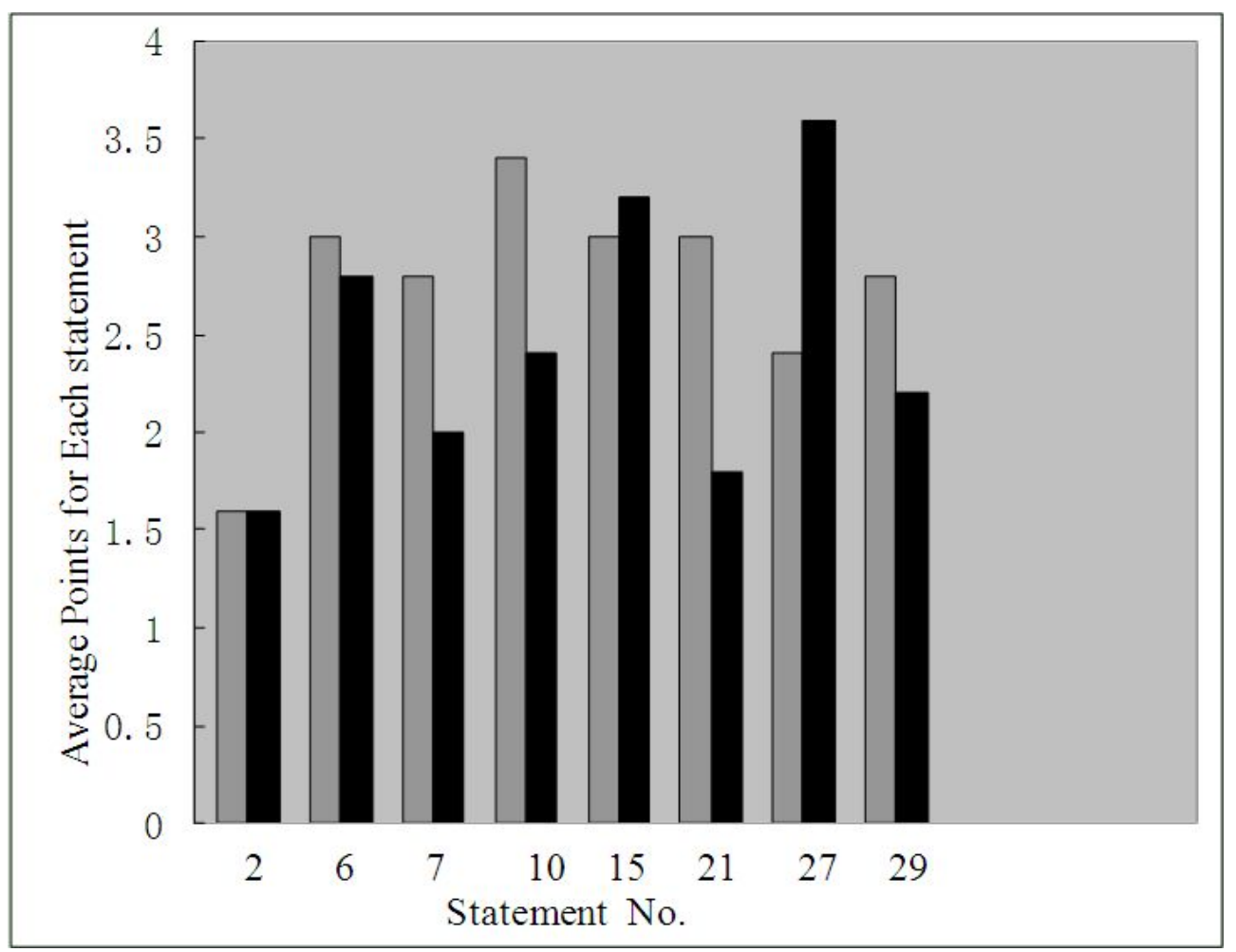

Figure 1. Changes in students' self-confidence in English 
From Figure 1, we can see that the average points of referring statements except statement 3, 5 in Q2 are all in the positive side of the scale. Here student B's remark "...From the practices I gained confidence..." well accounts for the change of the students.

The results above are quite easy to understand. In a traditional classroom, students often feel anxious to speak in front of the whole class. And only teachers provide encouragement to students. As a matter of fact, students often wish for others' failure because it increases their own chance of success (Kagan, 1994). This may lead to a hostile learning atmosphere in which students learn to recognize that if one gains, the others must lose. In contrast, there is more confidence connected with speaking in the smaller group (Long \& Porter, 1985). Besides, students can encourage and help one another. Therefore, the cooperative atmosphere can, as the results show, decrease anxiety among students, increase confidence, and greatly motivate them to work together.

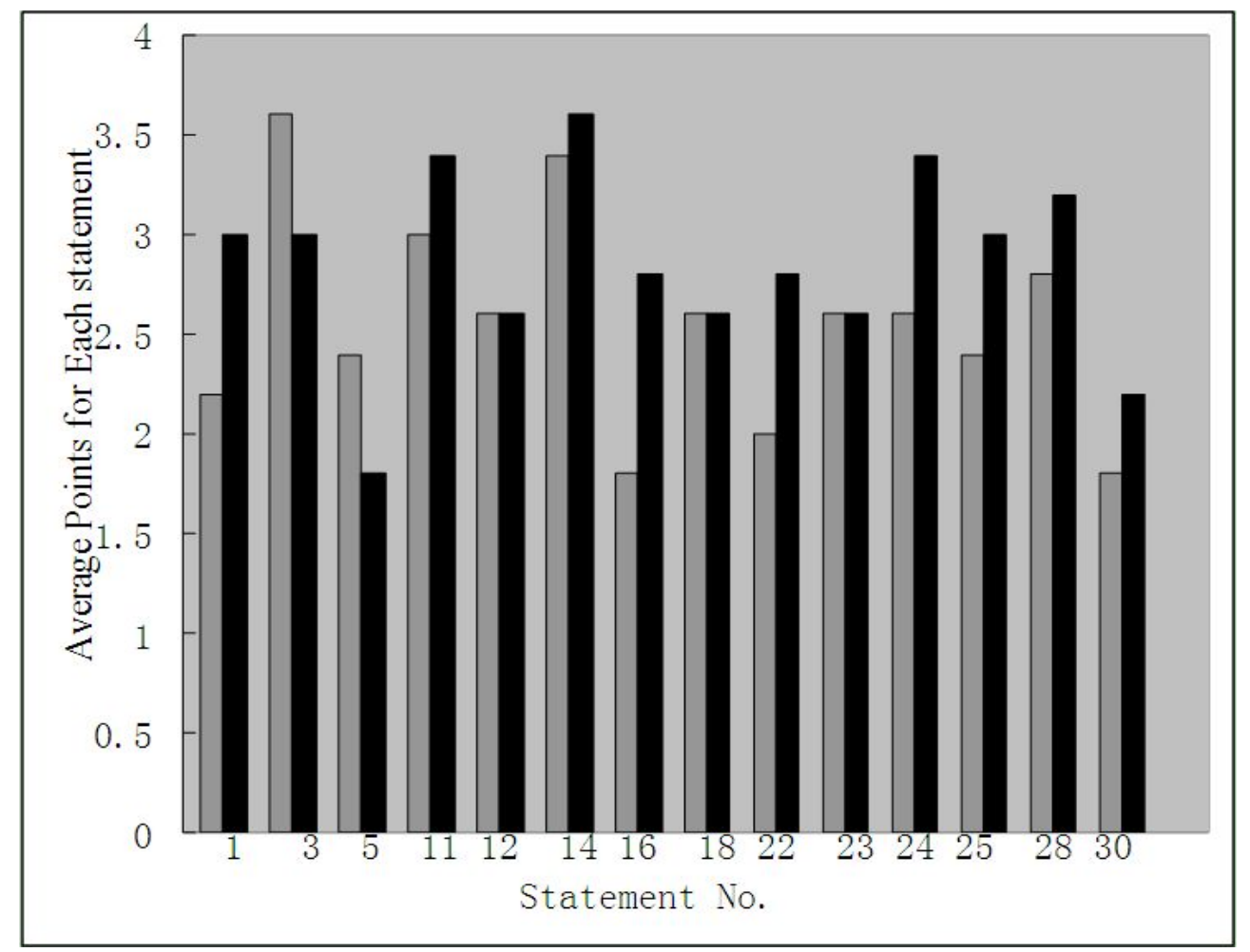

Figure 2. Changes on students' behaviors of anxiety

From Figure 2, we can see the average points about students' behaviors of anxiety had significantly decreased. These tendencies and their underlying reasons are unmistakably showed in student A's comment: "I am not afraid of being evaluated because I am not isolated and I can discuss with other members in my group."

The change is not only due to the co-operative and relaxed environment, but also due to the enhancement of the students' autonomy. Since they build up autonomy in co-operative learning and are successively motivated to practice a lot, they are really sure of their ability in English task and the anxiety that has troubled tern for so long has diminished little by little.

However, we should notice there are still two statements, 15 and 27, showed negative result. 


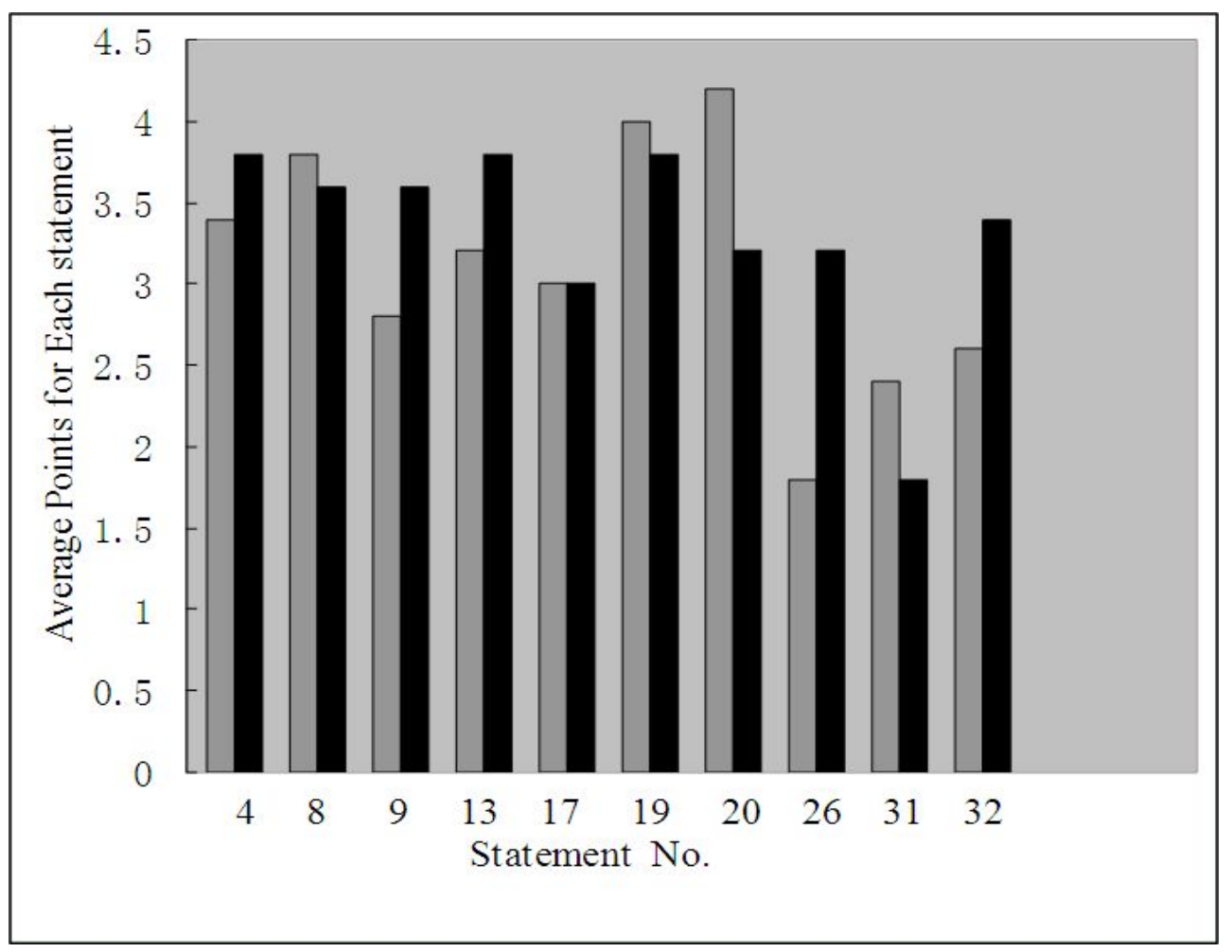

Figure 3. Changes on students' attitude towards English

From Figure 3, we can see the changes on students' attitudes towards English. The students become more willing to discuss questions with others and help others, especially as is illustrated in state 13, the average points in Q2 is much higher than in Q1. The comparison average points of Statement 4, 9 between Q1 and Q2 show that most students have higher motivation in co-operative learning English class than in a traditional class.

Based on above findings, reviewing the purpose of the study, it is concluded at last that co-operative learning do have some positive effects on improving the present passive situation in English classroom. It also helps activate their enthusiasm for and ease their language anxiety of participating in class activity. The co-operative language learning deserves to be recommended to Chinese teachers and students to bring a new life into the gloomy and monotonous English classroom.

Although we can see significant changes of the students, we can't overlook some statements still remain the same or even show the negative results.

\section{Discussion}

Although most of the results confirm the aspects of the literature and my assumption, there are three issues that arose from my action research which seem to be different from my assumption. Now I'm going to answer the third research question of this study: What possible difficulties do teachers have in implementing co-operative learning?

\subsection{Cultural Obstacles}

Many of the problems arose from my action research can be attributed to several important characteristics of traditional Chinese culture. These characteristics, although originating over five thousand years ago, have developed continuously over that period. They have become rooted in almost every segment of Chinese society and therefore must be regarded as influential guidelines in today's China.

The first of these characteristics is the issue of "face". This concept, called "mian zi" in Chinese, was first illustrated in English in Chen \& Xing (1997), who defined mian zi as "a reputation achieved through getting on in life, through success and ostentation" (p.45), and was later popularized as "face" by Zhang (1998). Zhang (2002) further elucidated face, stating that "gain or loss of face depends on an individual's ability to answer questions and do class work correctly" (p. 92). A co-operative group means the making of comments, arguments, 
and even criticism among members of the group. Therefore, with a peer response group, gain or loss of face is inevitable.

A second characteristic is that in a Chinese classroom the dignity and authority of the teacher cannot be challenged. Based on questionnaire statement 17 's selecting result, the majority students think the reliability to the knowledge from classmates is lower than that from teachers, and the knowledge from classmates is not overall as good.

More than 2,500 years ago, Confucius advocated the teacher's dignity and authority as "shi dao zun yan", which literally translates as "teacher" (shi) "way" (dao) and "respect" or "dignity" (zun yan), and can be glossed as "respect for the teacher". Therefore, Chinese students tend to ignore peers' comments on their work.

An associated idea that cannot be ignored is students' cultural expectations of appropriated roles of teachers and learners. In general, Chinese students tend to think that the only correct and unambiguous answer comes from the teacher, not from fellow students. This kind of passive methodology naturally affects the students' initiative to participate in discussions.

A third characteristic of Chinese classroom is students' weakness in speaking in and listening to English, a factor that works against group interaction. As a result, this weakness will lead Chinese students to feel nervous when they are speaking English in front of large audiences. This problem is in part the result of the traditional Chinese curriculum: the Chinese EFL curriculum focuses on reading rather than listening or speaking. As Zhang (2002) stated, "The Chinese place reading at the core of their English curriculum...the heart of the curriculum is reading"(p.46). Both English major and non-English major undergraduates normally take listening and speaking classes only for the first year or two of their four-year programme. Although, they are assumed to have learned enough to be able to listen to and speak English with a sufficient degree of fluency, in general this is not the case. Yule and Macdonald (1992) reinforce this strongly, writing that students "typically can say very little, and can hear even less" (p. 387)

Finally, there is the issue of collectivism, a cultural orientation that is highly misunderstood in the West. As Carson and Nelson (1992) point out, "Members of collectivist cultures believe that the collective, or group, is the smallest unit of survival" (p. 2). Indeed, the group is central to Chinese pedagogy.

However, as Chen \& Xing (1997) point out, "In Asia, the emphasis is on proper social relationships and their maintenance rather than any abstract concern for a general collectivist body. In a sense, it is a collectivism only among those bound by social networks" (p. 67).

Therefore, Gao (1992) wrote, "More likely than not, concern decreases with decreasing familiarity of the other. Concern for a person close to oneself (e.g., parent, spouse) is higher because interdependence has clearer consequences" (p. 232).

Because of this, Carson and Nelson (1992), write "The kinds of behaviors (e.g., exhibiting group loyalty and working for the collective good) that occur when Chinese students are interacting with members of their primary groups (ingroups) do not necessarily occur with those who are not members of their groups (outgroup members)"(p. 3).

Therefore, the teacher who arbitrarily assigns students to co-operative groups runs the risk of bunching outgroup members together; in this case, students will be highly reluctant to help each other. If the teacher uses ingroups, however, he or she runs the risk of teaming close friends; students may be afraid of upsetting the balance of relationships that occur in ingroups.

Given this understanding of these cultural obstacles, it is not reasonable to expect students to blindly accept co-operative learning rooted in the Western cultural framework. This can be seen from questionnaire II statement 18 's selecting result, namely, 40 percent of students think they cannot get accustomed to student-centered co-operative learning. Therefore, we need to consider the ways in which co-operative learning can be effectively adapted to the Chinese context. It takes time for those students who have strong sense of relying on teachers to get used to new role as a director of learning, so teachers should be most understanding, and helpful for them to change ideas and learning strategies to cultivate students' ability of self-study.

\subsection{Individual Difference}

In addition to cultural obstacles, individual difference also affects the efficacy of co-operative learning. In co-operative learning classroom, my colleagues and I observed that small number of students showed indifference to this approach, e.g. they don't communicate with other group mates on learning tasks, but are ready to think over questions independently and complete learning tasks independently. Even if they encounter 
difficulties in learning, they are likely to turn to a dictionary and other references instead of asking other group mates for help. Some students think task distribution in co-operative learning is not beneficial, because it is hard for students to master overall knowledge. In addition, learning relies mainly on individual effort, and need continuous accumulation, so cooperation in the classroom is not meaningful. Some students stated directly that they were 'fit' for individual learning, not co-operative learning with others.

In terms of this problem, we should keep a correct attitude towards it. Individual differences are mainly a difference in preferred learning style. From a cognitive perspective, learning style is divided into Field Independence and Field Dependence. Field-dependent persons tend to be more socialized, tend to derive their self-identity from persons around them, and are usually more empathic and perceptive of the feelings and thoughts of others, while field-independent persons tend to be generally more independent, competitive, and self-confident.

There are positive and negative characteristics to both field independence and field dependence. Different learning styles affect the amount of time students wish to spend, for example, in individual experimentation or reflection, or group discussion and processing. Therefore, teachers should guide students' learning style in implementing co-operative learning. For example, students should be encouraged to be field-independent during completion of individual task so that their interest can be motivated and creativity can be cultivated. While in group discussion, students should be encouraged to be field-dependent so that they can take active part in discussion, show opinions bravely, listen to and receive others' opinions, and work hard with group mates to finish group task perfectly for the group honour. Thus, their abilities of social communication, cooperation and esprit de corps can be strengthened.

While one goal of co-operative learning is to help students learn to get along with and work with all individuals in the class, there are sometimes personality differences which are so great that a member of the group may need to be re-assigned. If that student is unable to work with any other group, he or she may need to be given the opportunity to work alone during the group sessions. Over time, social isolation may provide sufficient motivation for renewed efforts at functioning within a group. Over time, as well, students who previously did not get along may come to develop respect or admiration for each other or even become friends through the co-operative learning process.

\section{References}

Carson, M., \& Nelson, G. L. (1992). Writing groups and the less proficient ESL Student. ESOL Quarterly, 2(2), $2-6$.

Chen, L., \& Xing, J. (1997). Co-operative Learning in China. Teaching English in China, 27, 35.

Christison, M. A. (1990). Co-operative learning in the EFL classroom. English Teaching Forum, 28(4).

Gao, Y. (1992). The relationship between linguistic competence and pragmatic competence. Modern Foreign Languages, 2.

Johnson, D. W., \& Johnson, R. T. (1989). Cooperation and competition: Theory and research. Edina, MN: Interaction Book Company.

Kagan, S. (1994). Co-operative learning. San Juan Capistrano, CA: Kagan Co-operative learning.

Knight, G., \& Bohlmeyer, E. M. (1990). Co-operative learning and achievement: Methods for assessing causal mechanisms. In Sharan, S. (Ed.), Co-operative learning: Theory and Research (pp. 1-7). New York: Praeger Publishers.

Kohonen, V. (1992). Experiential language learning: Second language learning as co-operative learner education. In D. Nunan (Ed), Collaborative Language Learning and Teaching (pp. 14-39). Oxford University Press.

Legutke, M., \& Thomas, H. (1991). Process and Experience in the Language Classroom. New York: Longman.

Long, M. H., \& Porter, P. A. (1985). Group work, interlanguage talk, and second language learning. TESOL Quarterly, 19, 207-228.

Putnam, J. W. (1993). Co-operative Learning and Strategies for Inclusion: Celebrating Diversity in the Classroom. Baltimore: Brookes publishing Co. Inc.

Totten, S., \& Sills, T. (1991). Co-operative Learning: A Guide to Research. New York: Garland Publishing Inc.

Wu, Y. (2002). Using Group Work Effectively: Suggestions on Using Group Work in ELT Classroom. Teaching English in China, 25(1), 5-10. 
Zhang, D. (2002). Group Learning - A Practical Strategy in Effective ELT. Teaching English in China, 25(1), 10.

\section{Copyrights}

Copyright for this article is retained by the author(s), with first publication rights granted to the journal.

This is an open-access article distributed under the terms and conditions of the Creative Commons Attribution license (http://creativecommons.org/licenses/by/3.0/). 